Revue

Revue de l'histoire des religions

de Ihistoire des religions

\title{
Figures de Noé de Gilgamesh au Coran
}

Avant-propos

Viviane Comerro

\section{OpenEdition}

Journals

Édition électronique

URL : https://journals.openedition.org/rhr/8459

DOI : $10.4000 /$ rhr.8459

ISSN : 2105-2573

Éditeur

Armand Colin

Édition imprimée

Date de publication : 1 décembre 2015

Pagination : 483-485

ISBN : 978-2-200-93012-7

ISSN : 0035-1423

Référence électronique

Viviane Comerro, "Figures de Noé de Gilgamesh au Coran », Revue de l'histoire des religions [En ligne], 4 | 2015, mis en ligne le 18 décembre 2015, consulté le 21 septembre 2021. URL : http:// journals.openedition.org/rhr/8459; DOI : https://doi.org/10.4000/rhr.8459 


\section{Figures de Noé de Gilgamesh au Coran Avant-propos}

Avant de devenir une figure typologique annonçant Moïse, le Christ ou Mahomet, Noé s'est construit à partir de ses précurseurs mésopotamiens, Ziusudra ou Vie de jours prolongés, Atrahasis ou J'ai trouvé ma vie, et Uta-napishti le Supersage, qui survivent à un déluge dont la représentation a elle aussi varié, allant de l'ouragan céleste de la colère des dieux venant détruire une ville, ou du cataclysme originel détruisant toute vie in illo tempore, au commencement de l'histoire humaine, jusqu'à l'annonce du cataclysme igné de l'eschaton qui précédera le Jugement dernier, dans lequel le feu se substitue à l'eau.

D'un texte à l'autre, la cause du déluge varie : menace d'un chaos primitif qui verrait les étoiles abandonner leur « course véridique », jalousie des dieux à l'égard d'une humanité bruyante et laborieuse, affliction du dieu créateur devant la méchanceté de l'homme qui ravage la terre... Enfin, c'est la figure et le destin du survivant du déluge qui se transforment. Le Noé biblique apparaît ainsi plus pleinement humain que ses prédécesseurs mésopotamiens, lui qui ne bénéficie pas de l'immortalité auprès des dieux, mais seulement d'une longue vie au milieu des siens.

Une vision comparatiste superficielle pourrait expliquer les changements opérés par le simple passage d'une religion à une autre. Or d'une religion à l'autre, nous constatons que ce qui se transmet est aussi important que ce qui se transforme. Il en va de même à l'intérieur d'une seule et même religion : le contexte culturel différent dans lequel vivent les générations qui se succèdent fait naître un désir de renouveler l'héritage et de le développer, tandis que la transmission dont ils se savent redevables engendre un désir 
aussi fort de le conserver. Au sein même du corpus biblique, la figure de Noé est associée à un riche ensemble de traditions véhiculées, relues et réinterprétées en fonction de nouveaux contextes.

Ainsi la tradition juive à l'époque du Second Temple, loin de s'en tenir au texte de la Genèse, développe une approche théologique de Noé dans ses figures de prêtre, d'exorciste, de législateur, de prophète, de récipiendaire d'un livre enseigné par les anges ou de quasi-messie doté d'une naissance miraculeuse. Noé devient le maître de la terre qu'il partage entre ses fils. Littérature apocryphe dira-t-on... Et pourtant ne voit-on pas, un peu plus tard, les rabbins user de la même liberté à l'égard du texte biblique qu'ils « réécrivent » en l'interprétant, en l'amplifiant, ou en l'associant à d'autres versets pour rendre le personnage de Noé plus ambivalent, plus complexe, plus humain dans leur quête d'une justice de Dieu infaillible?

L'entreprise exégétique de Philon d'Alexandrie, dont hériteront Origène et Amboise dans la tradition patristique chrétienne, fait de Noé et de ses fils des forces extérieures agissant pour la perdition de l'âme ou son salut. L'allégorie et la recherche du symbole dans le moindre détail de l'Écriture outrepassent-elles la compréhension $\mathrm{du}$ texte? Et faut-il distinguer l'allégorie de la dimension typologique si présente dans l'exégèse chrétienne ? Ces questions, comme on l'aura reconnu, sont empruntées au Sacramentum futuri de Jean Daniélou dont un long chapitre est consacré à la typologie noachique ${ }^{1}$. Cet ouvrage fondateur est encore d'une telle importance qu'il peut pallier l'absence dans ce numéro thématique d'un article sur l'exégèse chrétienne grecque et latine du texte de Genèse 7-9. Pourtant, à la lecture de tous les articles ici réunis, un autre questionnement se dégage, moins attaché à l'orthodoxie des seules traditions vétéro- et néotestamentaires, mais plus sensible à la « puissance » des textes et à la créativité de leurs interprètes. Une créativité rarement mue par le simple goût de la narration, encore que cet aspect ne soit pas négligeable, mais plus souvent combinée par divers moyens à une réflexion théologique, autour de la question de la théodicée en particulier.

1. Sacramentum Futuri. Etudes sur les origines de la typologie biblique, Paris, Beauchesne, 1950, p. 55-94. 
Pour autant, l'exégèse chrétienne n'est pas absente de ce numéro puisqu'elle fait l'objet d'un de ses plus longs articles à travers la tradition syriaque, qui nous conserve des éléments interprétatifs d'origine juive dans son passage vers le christianisme arabe puis, de façon détournée, vers l'islam. Ephrem le Syrien annoncerait-il dans son expression poétique incomparable qui rend visible l'invisible, l'expression tout aussi incomparable du Coran dont on a fait un genre littéraire à part entière, ne sachant le situer ni dans la prose ni dans la poésie ? C'est d'ailleurs sous cet aspect de la composition textuelle qu'est abordée, dans ce numéro, la figure de Noé dans l'islam. Délaissant les sentiers battus depuis le XIX ${ }^{\mathrm{e}}$ siècle, on s'est attaché à rendre manifeste le style de la théologie coranique, puis les amplifications narratives de l'exégèse qui font voler en éclats le cadre narratif du Coran.

Il nous reste à remercier tous les chercheurs qui se sont côtoyés l'espace d'un moment dans l'arche de la $R H R$, sur les eaux tumultueuses de l'interprétation des textes.

vivianedepremare@orange.fr 